\title{
O CETICISMO, ENTRE MAIMON, FICHTE E HEGEL ${ }^{1}$
}

\author{
SCEPTICISM, BETWEEN MAIMON, FICHTE AND HEGEL
}

\author{
Diogo Ferrer ${ }^{2}$
}

Recebido em: 11/2020

Aprovado em: 11/2020

\begin{abstract}
Resumo: Este artigo apresenta uma perspectiva comparativa de algumas das respostas ao ceticismo no período da filosofia clássica alemã. Parte-se de uma exposição da crítica de S. Maimon a Kant, nomeadamente acerca da aplicabilidade dos conceitos puros à realidade empírica, e da influência deste problema sobre a Doutrina da Ciência de J. G. Fichte.

São abordadas então as principais teses dos Fundamentos da Doutrina da Ciência de 1794/1795 de Fichte no que toca à possibilidade de uma filosofia sistemática construída a partir de primeiros princípios. Uma referência à discussão de Hegel, em 1802, acerca do significado e da relação entre o ceticismo antigo e moderno, introduz a exposição da resposta de Hegel ao ceticismo na Fenomenologia do Espírito, e à fundamentação do conhecimento na Ciência da Lógica.

Além de mostrar a importância de Maimon para o desenvolvimento da filosofia clássica alemã, três teses são defendidas neste artigo: primeiro, que as respostas ao ceticismo tanto de Fichte quanto de Hegel aceitam os termos da discussão colocados pelo ceticismo; segundo, que ambos propõem refutações internas do ceticismo; e, terceiro, que o ceticismo, e a sua refutação interna, podem ser entendidos como um fio de ligação entre as diferentes posições filosóficas estudadas.
\end{abstract}

Palavras-chave: Maimon, Fichte, Hegel, Ceticismo.

\begin{abstract}
This article provides an overview of some significant responses to scepticism in German classical philosophy. I start with the exposition of S. Maimon's criticism to Kant about the applicability of pure concepts to the empirical reality and the influence of this problem on J. G. Fichte's Wissenschaftslehre.

I expose the main theses of Fichte's 1794/1795 Foundations of the Entire Wissenschaftslehre, from the point of view of the possibility of a systematic philosophy built upon first principles. Next, I consider Hegel's 1802 discussion of the meaning and relationship of ancient and modern scepticism. This will allow me to introduce Hegel's response to scepticism in the Phenomenology of Spirit and the question about the grounds of knowledge in the Science of Logic.

In addition to showing the relevance of Maimon for the development of classical German philosophy, three theses are defended in the article: first, that both the Fichtean and the Hegelian answers accept the terms of discussion set by scepticism; second, that both present internal refutations of scepticism; and finally, that scepticism and its internal refutation can be understood as a thread connecting different philosophical positions in German classical philosophy.
\end{abstract}

Keywords: Maimon, Fichte, Hegel, Scepticism.

\footnotetext{
${ }^{1}$ As ideias deste texto foram originalmente apresentadas como conferência no encerramento do Colóquio de Filosofia Alemã da Universidade Federal do ABC: Fundamentação Filosófica e Ceticismo, Universidade Federal do ABC, São Bernardo do Campo, São Paulo, Brasil, 4 de outubro de 2018. Agradeço muito especialmente ao Prof. Luís Barrére Martin o convite para essa intervenção.

${ }^{2}$ Universidade de Coimbra, Centro de Estudos Clássicos e Humanísticos - CECH.
} 
Para os seus seguidores e continuadores no período da Filosofia Clássica Alemã, o conhecidíssimo elogio de Kant a Hume a propósito do seu "sono dogmático", e do ceticismo como condição da descoberta da filosofia crítica não é, de todo, um cumprimento retórico ocasional. Logo na primeira frase do Conceito da Doutrina da Ciência de Fichte, que abre o caminho, em 1793, para a filosofia sistemática pós-kantiana e o idealismo alemão, ressoa ainda o referido elogio de Kant ao ceticismo: "pela leitura dos novos céticos, em particular do Enesidemo, e dos excelentes escritos de Maimon, o autor deste tratado ficou totalmente convencido daquilo que já anteriormente lhe parecia altamente provável: que a filosofia, mesmo através dos mais recentes esforços dos homens mais perspicazes, ainda não foi elevada ao estatuto de uma ciência evidente." ${ }^{3}$ Schulze, o autor do Enesidemo, e Maimon são, pois, as duas figuras céticas que assumem para Fichte, desde o seu primeiro escrito programático, um papel similar ao que Hume teve para Kant.

O contributo do Enesidemo de Schulze para o pensamento de Fichte é referido com muita frequência, principalmente porque a sua crítica à tentativa de Reinhold de fundar a filosofia sobre um "facto [Tatsache] da consciência" deu um impulso decisivo a Fichte. Segundo Schulze, a filosofia transcendental, que pretende fundar todo o domínio da representação dos factos, não se pode fundar, sem circularidade, sobre um outro facto. A resposta de Fichte a esta crítica levou-o a utilizar, com um novo sentido, o termo, infelizmente intraduzível, "Tathandlung"4 que substitui, como princípio fundamental da consciência e dos factos nela presentes, a componente da "coisa" (Sache, presente em "Tatsache"), pela da "ação" (Handlung). A filosofia transcendental não se pode fundar num facto (Tatsache), mas somente num "ato" primeiro ou originário (Tathandlung).

O contributo cético de Maimon para o desenvolvimento dos sistemas posteriores do Idealismo Alemão deve, por sua vez, ser entendido de um outro modo. Nos Fundamentos da Doutrina da Ciência, em 1794, Fichte fala, tudo indica, de Maimon quando se refere, sem o nomear, a "um dos maiores pensadores do nosso tempo", 5 não só a propósito do ceticismo, mas

\footnotetext{
${ }^{3}$ Fichte, GA I/2, 109.

${ }^{4} \mathrm{O}$ termo "Thathandlung" era utilizado desde o Séc. XVII, com incidência jurídica, para designar uma ação violenta ou, noutros contextos, uma façanha. Em Fichte, designa um ato originário, e sem pressupostos, de livre autoposição: "uma atividade que não pressupõe nenhum objeto, mas que o produz, no qual, portanto, o agir [handeln] se torna imediatamente ato [that]." (Deutsches Wörterbuch von Jacob und Wilhelm Grimm, Leipzig 1854-1961. Online-Version vom 04.03.2020)

${ }^{5}$ Fichte, GA I/2, 368.
} 
sobretudo da imaginação, cuja definição por Maimon é uma precursora importante para a Doutrina da Ciência de Fichte (Wissenschaftslehre).

\section{Maimon contra o "criticismo dogmático"}

Assim, Fichte saúda Maimon, juntamente com o Enesidemo de Schulze, como o cético que o convenceu da necessidade de reformular a filosofia transcendental sobre novas bases. No entanto, juntamente com o ceticismo, Maimon introduziu uma série de conceitos inovadores da maior importância para a Doutrina da Ciência de Fichte. Por intermédio desta, estes conceitos são também significativos para o pensamento de Hegel, a que ela ajudou a dar forma. Hegel não terá lido sequer Maimon, uma vez que não o parece citar em nenhum momento da sua obra, mas não deixou de receber alguns aspectos do seu pensamento, destilados através da Doutrina da Ciência de Fichte.

A crítica cética de Maimon a Kant parte daquelas que entende serem as duas pontas soltas da filosofia transcendental kantiana. Por um lado, retorna explicitamente ao empirismo de Hume, ao mesmo tempo em que, por outro, retoma também Leibniz. A partir da mesma ligação entre empirismo e racionalismo com que Kant levou a cabo uma filosofia transcendental sistemática, Maimon pretende, pelo contrário, retirar consequências céticas. $\mathrm{O}$ novo instrumentário de Maimon, que lhe permitirá alterar os dados da questão, incluirá o conceito de diferencial, uma concepção alterada de síntese, mais próxima de Hume do que de Kant, um novo papel concedido à imaginação e uma alteração significativa da definição do que podemos denominar a diferença crítica, ou seja, a diferença entre entendimento e sensibilidade. ${ }^{6}$

Maimon alcançou alguns resultados construtivos significativos acerca das possibilidades e do sentido da filosofia transcendental, que Fichte irá assimilar largamente. Mas alcançou também um resultado negativo - que justifica a classificação assumida de Maimon como cético -, que é a sua crítica ao uso das categorias do entendimento por Kant. Maimon centra a sua crítica ao transcendentalismo kantiano na categoria de causa e efeito. Recuperando a crítica cética de Hume sob uma nova forma, Maimon argumenta que, numa relação de

\footnotetext{
${ }^{6}$ Para uma apresentação e breve discussão desta diferença em Kant, e a sua crítica por Maimon, vide H. E. Herrera, "La discusión de Salomon Maimon con el intento de vinculación de sensibilidad y entendimiento en la Crítica de la razón pura de Immanuel Kant," in Anuario Filosófico, XLIII/3 (2010), 561-587. F. Beiser apresenta duas razões por que Maimon acredita que o "gulf" entre as faculdades é "infranqueável" (Beiser, "Maimon and Fichte," in Salomon Maimon: Rational Dogmatist, Empirical Skeptic: Critical Assessments, ed. Gideon Freudenthal (Boston: Kluwer, 2003, 233-248), 237), a saber, a heterogeneidade radical das faculdades (237) e a ausência de um "critério" para a aplicação das faculdades a "intuições específicas" (238).
} 
causalidade, apenas se pode verificar experimentalmente uma alteração nas posições relativas, movimentos, formas ou estados dos corpos, mas não se pode distinguir qual deve ser considerada a causa e qual o efeito senão através de um conhecimento empírico da natureza ou qualidade de cada um dos corpos. ${ }^{7}$ Segundo Maimon, "somente a espécie de relação entre os objetos entre si é cognoscível na percepção, mas não os elos dessa relação" ${ }^{8} \mathrm{em}$ particular ou em concreto. Maimon defende, ademais, que o juízo hipotético é uma relação necessária apodítica - entre sujeito e predicado e, por isso, a categoria do entendimento com a mesma função, i.e., a causalidade, tem também de se traduzir na aplicação de uma regra apodítica e determinante do entendimento. Mas uma regra apodítica significa que "uma síntese só é possível porque uma das suas partes constituintes não pode ser pensada sem a outra." ${ }^{99}$ Ao nível da sensação, ou da percepção, pelo contrário, estamos inevitavelmente perante sequências espácio-temporais contingentes, produzidas pela imaginação, onde um objeto, ou uma nota característica (Merkmal), pode ser pensada sem a outra. ${ }^{10}$ A conclusão de Maimon é que o entendimento dispõe, efetivamente, do conceito de causalidade como uma regra e função necessária da experiência objetiva, mas a sua aplicação concreta está dependente do conhecimento de fatores apenas empiricamente determináveis, e não de uma síntese a priori. A aplicação da categoria, por conseguinte, não pode ser mais do que uma aproximação assimptótica, ou seja, um diferencial. Por conseguinte, “o conceito de causa não é uma categoria, mas uma ideia, da qual nos podemos sempre aproximar no seu uso, mas que jamais podemos alcançar. [...] E o mesmo se passa com todas as outras categorias."11

Maimon chega assim ao extraordinário conceito de "ideia do entendimento", o que significa que todo o domínio da experiência é regido não por uma determinação integral segundo conceitos, conforme pretendia Kant, mas por ideias. Como resultado, a relação crítica entre sensibilidade e entendimento deve ser reconsiderada. A sensibilidade passa a ser entendida como um diferencial em relação à categoria ou ideia. O problema kantiano da relação

\footnotetext{
${ }^{7}$ Maimon, Versuch über die Transzendentalphilosophie (ed. F. Ehrensperger, Hamburg: Felix Meiner, 2004$), 124$.

8 "nach mir hingegen ist nur diese Art Beziehung der Objekte auf einander, nicht aber die Glieder dieser Beziehung in der Wahrnehmung erkennbar." (ib. 122)

9 "Eine Synthesis ist nur darum möglich, weil der eine ihrer Bestandteile ohne den andern nicht gedacht werden kann." (ib. 75)

${ }^{10}$ M. Guéroult mostra que "com efeito, se as partes de uma síntese podem ser concebidas como separáveis, é porque estão ligadas entre si não por uma necessidade objetiva, mas por uma simples coexistência no tempo e no espaço. A síntese é então sem fundamento, é arbitrária, tem a sua fonte não no entendimento, mas na imaginação. Ela não nos fornece um «verdadeiro objeto» (essentia realis), mas um totum de características (Merkmal)" (Guéroult. La philosophie transcendantale de Salomon Maimon, Paris: Félix Alcan, 1929, 47). Estas sínteses não são mais do que "juízos subjetivos, tornados necessários pelo hábito” (48). Vide também, 101, 104.

11 "Dieser Vorstellungsart zufolge ist also der Begriff von Ursache keine Kategorie, sondern eine Idee, zu der man sich im Gebrauche immer nähern, die man aber nie erreichen kann.” (Maimon, Versuch, 245)
} 
entre conceito e intuição pode ser então resolvido, de uma maneira mais satisfatória do que na dedução transcendental de Kant, nomeadamente, pela tese de que "a sensibilidade em nós é o entendimento incompleto."12 A passividade própria da afecção (Leiden) sensível é, por isso, também ela em geral "uma mera ideia, da qual sempre nos aproximamos mais por uma redução da consciência," 13 mas que não tem sentido fora dessa aproximação ideal. E, consequentemente, as formas lógicas, ou as categorias devem ser consideradas como condições já da própria sensação. ${ }^{14}$ Para o conceito kantiano da coisa em si, a consequência inevitável é que "a representação de uma coisa só se diferencia da própria coisa por uma menor completude."15

Mas Maimon concorda com Kant em que as ideias não têm qualquer uso empírico determinante, e toda a experiência objetiva, bem como a ciência natural, são constituídas somente por um uso regulador da razão. Maimon conclui, “com o meu amigo cético D. Hume, contra o dogmatismo crítico, que as formas lógicas do pensar [...] não têm um uso imediato nos objetos sensíveis da natureza, mas unicamente por meio de uma indução completa," a qual não é objetivamente realizável. ${ }^{16}$ Perante a nova síntese entre empirismo e racionalismo levada a efeito por Maimon, a filosofia transcendental de Kant é considerada um novo tipo de dogmatismo, apodada então com o estranho epíteto de "dogmatismo crítico".

Em geral, conforme Fichte observará nos Fundamentos da Doutrina da Ciência de 1794/1795, o ceticismo de Maimon centra-se no problema da passagem da lógica à realidade: "o ceticismo de Maimon funda-se, em última instância, sobre a questão acerca da nossa autorização para a aplicação da categoria à realidade." 17 E, nas palavras de Maimon, "não

\footnotetext{
12 "die Sinnlichkeit bei uns der unvollständige Verstand ist." (ib. 103) Como explica F. Beiser, "para Fichte, o desafio principal de Maimon vinha do próprio cerne do seu «ceticismo crítico»: a sua crítica à dedução transcendental. A essência da crítica de Maimon é que Kant não é capaz de resolver o problema por detrás da dedução - 'Como é que os conceitos a priori se aplicam à experiência, se não derivam dela?' - em virtude do seu dualismo rígido e estrito entre entendimento e sensibilidade" (Beiser, "Maimon and Fichte," 234). Procurei mostrar em Ferrer, O Sistema da Incompletude: A Doutrina da Ciência de Fichte de 1794 a 1804 (Coimbra: Imprensa da Universidade de Coimbra, 2014), que Fichte considera como central para a sua Doutrina da Ciência a noção de incompletude a qual, como observamos aqui, era oriunda de Maimon.

13 "díeses ist aber eine bloße Idee, zu der wir uns durch Verminderung des Bewußtseins immer nähern" (Maimon, Versuch, 95).

${ }^{14} \mathrm{Ib}$. cf. 120.

15 "Die Vorstellung eines Dinges ist vom Dinge selbst bloß durch eine mindere Vollständigkeit unterschieden" (ib. 109-110). Para esta questão vide F. Vermeiren, "Radical Immanence of Thought and the Genesis of Consciousness: Salomon Maimon", in Kant-Studien (2019) 110/2, 272-289, esp. 276-277.

16 "mit meinem skeptischen Freunde D. Hume gegen das kritische Dogmatism, daß die logischen Formen des Denkens $[\ldots]$ auch von den sinnlichen Gegenständen der Natur unmittelbar keinen Gebrauch haben, sondern bloß vermittelst einer vollständigen Induktion.” (Maimon, Versuch, 248)

${ }^{17}$ Fichte, GA I/2, 261.
} 
existem leis gerais a priori da experiência (e.g., tudo tem uma causa, etc.)," uma vez que "a filosofia crítica não é capaz de mostrar a sua realidade."18

\section{Fichte: Contra o ceticismo, a radicalização do ceticismo}

Devemos perguntar então se, e como o ceticismo continua operante na filosofia póskantiana, e em que medida Fichte integra estes elementos negativos e positivos que, como vimos, saudou em Maimon. Fichte não usa a mesma terminologia de Maimon. Alguns vocábulos essenciais de Maimon desaparecem, como "ideia do entendimento" e "diferencial". Substantivamente, no entanto, Fichte integrou o essencial dos elementos positivos de Maimon e, penso eu, desenvolveu o idealismo transcendental num sentido de uma incompletude sistemática comparável às concepções de Maimon. Segundo Fichte, a incompletude ideal do sensível postulada por Maimon é um termo essencial do sistema da razão, e a aplicação da categoria somente um processo de determinação definitivamente aberto.

A fim de entender o modo como Fichte lida com o ceticismo na sequência de Maimon e Schulze, dois aspectos deverão ser considerados: por um lado, o seu estabelecimento de princípios a priori para toda a filosofia e, por outro, a sua definição do conceito de realidade.

O primeiro princípio de Fichte, a já referida Tathandlung, ato originário, é uma resposta ao escolho cético de Schulze acima referido. Assim, Fichte entende o eu não como um facto ou uma representação, mas como um ato, tomado como um princípio, com uma constituição e estrutura conceptuais radicalmente diversos dos factos e representações que ele deve fundar. $\mathrm{Na}$ abordagem da relação do primeiro princípio de Fichte com o ceticismo, dever-se-á notar, embora o tema não seja enunciado explicitamente pelo autor, que o princípio com o eu absoluto deve ser capaz resistir aos tropoi principais do ceticismo antigo, nomeadamente os que pretendem refutar qualquer fundamentação de princípio para o conhecimento. De acordo com estes tropoi, a fundamentação do conhecimento tem obrigatoriamente de caber em uma de três modalidades: ou num regresso ao infinito; ou numa circularidade; ou numa pressuposição. Registe-se que esta questão ficou conhecida em décadas recentes sob o nome de trilema de Münchhausen, ${ }^{19}$ baseado na história do famoso Barão que se salvou de se afundar em um

\footnotetext{
${ }_{18}$ Maimon, Streifereien im Gebiete der Philosophie (in Gesammelte Werke, vol. 4, ed. Valerio Verra, Hildesheim: Georg Olms, 1970), 53 - tradução minha.

${ }^{19}$ A busca de uma fundamentação última "conduz a uma situação com três alternativas, que parecem todas elas inaceitáveis, isto é: a um trilema que eu gostaria de chamar o Trilema de Münchhausen, devido à analogia entre a nossa problemática e o problema que o conhecido barão enganador teve uma vez de resolver" (H. Albert, Traktat über kritische Vernunft, Tübingen: J. C. B. Mohr (Paul Siebeck), 1991, 15). A mesma dificuldade é também
} 
pântano puxando-se a si próprio pelos bigodes, e trazendo consigo ainda por cima o seu cavalo bem agarrado às esporas - história aliás que tinha já sido recordada a Fichte por Mme. de Staël, bem ao jeito do ceticismo de bom tom nas soirées dos salons littéraires. ${ }^{20}$

Segundo os tropoi antigos, a fundamentação primeira do conhecimento seria impossível. Com efeito, no caso do regresso ao infinito não há, por definição, um primeiro princípio capaz de fundar; no caso da circularidade, a fundamentação é dependente do fundado; a mera pressuposição, por fim, equivale precisamente à admissão do princípio como infundado. Esta dificuldade está subjacente à crítica cética de Schulze ao princípio definido como um facto da consciência, e a resposta de Fichte a Schulze tem de poder então resistir a estes argumentos. Assim, no primeiro princípio de Fichte não há, em primeiro lugar, regresso infinito, porque o princípio não é só mais um facto, a carecer de fundamento, mas um ato, estrutural e conceptualmente diverso dos factos que ele deve fundar. Em segundo lugar, o princípio de Fichte não enferma de circularidade, conquanto reivindica uma validade autónoma - a chamada autoposição - que não deriva daquilo que funda. E, finalmente, não constitui um simples pressuposto porque não é algo de assumido sem justificação, mas fundado, nomeadamente em si próprio. Um princípio capaz de autofundamentação é, com efeito, o único meio de evitar os tropoi 'Münchhauseanos' ou de Agrippa. E deve observar-se que esta condição de autoposição está em inteira coerência com o carácter de autonomia e liberdade atribuído ao princípio. ${ }^{21} \mathrm{O}$ princípio da autoposição corresponde à posição da liberdade como princípio. Esta é autofundada porque é, por definição, autónoma e transparente a si própria.

Uma parte da estratégia anticeticismo de Fichte consiste, assim, em estabelecer um princípio que, por definição, se autossustenta. Mas o que garante que este princípio, que se define como fundando-se a si mesmo, não é um mero juízo analítico que se limita a devolver aquilo que lá colocamos, uma simples definição formal ou nominal sem conteúdo real, ou um

\footnotetext{
denominada o "trilema de Agrippa". Para os tropoi de Agrippa no ceticismo antigo vide D. H. Heidemann, Der Begriff des Skeptizismus: Seine systematischen Formen, die pyrrhonische Skepsis und Hegels Herausforderung, Walter de Gruyter: Berlin / New York, 2007, 43-44, 50ss. Sobre a relação de Fichte com o trilema, vide D. Breazeale, "Fichte, Skepticism, and the 'Agrippan Trilemma'," in Fichte-Studien 44 (2017), 3-16.

${ }^{20}$ Acerca do encontro de Mme. de Stäel com Fichte em Berlim, em 1804, e a sua boutade sobre a Doutrina da Ciência, vide X. Léon, Fichte et son temps II: Fichte à Berlin (1799-1813), Paris: Armand Colin, 1924, 381-382.

${ }^{21}$ Como D. Breazeale mostra, para Fichte, "a intuição puramente filosófica funda-se, em última instância, numa crença prático-moral na realidade da interpretação normativa quotidiana." Assim, a resposta de Fichte ao ceticismo "não assenta, finalmente, sobre algum argumento, mas sobre um ato de vontade - a decisão de não renegar aquilo que um agente considera ser a sua própria «essência» como um agente livre, moralmente obrigado" (Breazeale, "Fichte, Skepticism, and the "Agrippan Trilemma", 13, 16). Para o "primado da razão prática" na Doutrina da Ciência, vide D. Breazeale, "Skepticism and Wissenschaftslehre" (in D. Breazeale, Thinking Through the Wissenschaftslehre: Themes from Fichte's Early Philosophy, Oxford: Oxford University Press, 2013), 249, 266, 267, que oferece também um tratamento extensivo da relação de Fichte com o ceticismo no período de Iena.
} 
simples pressuposto? O carácter material e real do princípio está atestado pela identidade do eu, registrada na experiência real da consciência de si e da liberdade - sem se fundar, no entanto, nesta familiaridade e experiência como um facto, o que é deixado bastante claro logo no $\S 1$ dos Fundamentos da Doutrina da Ciência.

No que se refere ao desafio de Maimon à filosofia transcendental, a proposta de Fichte integra, como se disse, diversos elementos céticos, procurando contudo mostrar que a realidade não pode ser reduzida nem à mera forma lógica do pensamento, nem à percepção empírica, mas tem de conter condições universais e necessárias. A filosofia transcendental define a realidade de modo tal que esta é capaz de suportar juízos sintéticos a priori, como um espaço próprio, situado entre a mera forma lógica do pensamento e a realidade empírica particular. Maimon intitulou a sua obra principal Ensaio sobre a Filosofia Transcendental, mas priva, na verdade, o espaço transcendental da sua principal característica, de não ser nem lógico, nem tão-pouco somente empírico, tornando-o meramente imaginativo ou fictício. Para Maimon, o espaço da experiência é um domínio apenas regulativo e assimptótico, cuja realidade é produzida pela imaginação, a qual não tem uma verdadeira capacidade objetivadora da realidade. Contrariamente à posição de Fichte, a imaginação que constitui a realidade não é, segundo Maimon, mais que um "Erdichtungsvermögen", uma "faculdade de invenção", é somente a posição concomitante no tempo e no espaço das diferentes notas características do objeto, sem verdadeira síntese. Uma síntese, como se referiu, exige a impossibilidade de pensar separadamente as características do objeto, o que não acontece com os produtos da imaginação. ${ }^{22}$ A imaginação, segundo Maimon, constitui o objeto sempre de modo apenas incompleto, inacabado no tempo e nas suas relações espaciais, projetando somente, como uma ficção, a sua completação. ${ }^{23}$ Ora, à projeção corresponde a ideia, não o conceito ou a categoria. Poder-se-ia então justamente questionar em que medida, nestas condições, a filosofia de Maimon merece o nome de filosofia transcendental.

Maimon desconectou, assim, precisamente aquilo que a dedução transcendental de Kant pretendia ligar, ou seja, a presença inevitável, na experiência, dos elementos universais e necessários implicados na síntese a priori, por um lado, com a própria possibilidade da experiência consciente, ou com um eu capaz de auto-reflexão, por outro. Esta é a questão que Fichte toma como o grande tema e argumento dos seus Fundamentos da Doutrina da Ciência. Trata-se de ligar a presença, na experiência, de elementos universais e necessários, quer dizer,

\footnotetext{
${ }^{22}$ Cf. Maimon, Versuch, 61.

${ }^{23}$ Cf. ib., 242.
} 
sintéticos a priori, à própria possibilidade da experiência consciente, ou seja, ao facto de que a experiência ocorre necessariamente para um eu capaz de autorreflexão. Uma vez que, como vimos, Fichte considera válida a crítica cética de Maimon a Kant, Fichte aceita também que Kant não teria sido capaz de ligar suficientemente os dois elementos que definem o espaço transcendental, a presença de princípios a priori na experiência objetiva, e a sua necessária referência a um ser consciente de si. Ou, dito de outro modo, haveria que mostrar, contra Maimon, que a realidade só é real, ou objetiva, na medida em que contiver em si elementos universais e necessários. A tarefa de Fichte na sua primeira apresentação da Doutrina da Ciência em 1794/1795 foi a de restaurar esta ligação, que Kant não teria conseguido fundamentar suficientemente.

O ponto central da argumentação de Fichte é mostrar que não há realidade, para o eu e em geral, senão com base em princípios a priori, universais e necessários. E, por isso, a primeira categoria que Fichte deduz a partir dos princípios da Doutrina da Ciência é justamente a categoria da realidade, que é um derivado direto da ação originária de autoposição do eu. Se, considerando a autoposição do eu, "abstrairmos de todo o juízo, como ação determinada, e olharmos somente para a espécie de ação [...] do espírito humano em geral, temos a categoria da realidade." 24 A ação do eu absoluto, de que Fichte parte como primeiro princípio, tem a forma da realidade, ou seja, a realidade é aquilo que é posto no e para o eu absoluto ou, acrescente-se, que pode ser posto para a intuição imediata do eu finito.

O conceito transcendental de realidade é então definido, no seu âmbito geral e ainda indeterminado, como o domínio do que é na, ou para a autoposição do eu. Assim, à partida, a forma da realidade não é dada nem pela lógica formal, nem empiricamente. Quanto à lógica formal, pelo contrário, é esta que, como uma abstração, depende da atividade do eu. No que se refere ao domínio empírico, a sua realidade só pode ser dada na medida em que é subsumida à categoria da realidade.

Mas se a realidade deve ser posta para o eu, i.e., sujeita à reflexão do eu, o ato puro da autoposição tem também de ser determinado por alguma limitação, a qual é fornecida pelo ato de antagonismo, ou oposição atribuído pelo eu ao não-eu que se lhe opõe. O eu só pode alcançar a consciência de si - e, também, a consciência da realidade - se o não-eu se opõe e limita a sua atividade de pura autoposição. Os modos da consciência de si do eu são os modos de limitação da atividade incondicionada do eu absoluto pelo não-eu. E, do mesmo modo, esses modos de

\footnotetext{
${ }^{24}$ Fichte, GA I/2, 261.
} 
limitação, que são os modos da interação entre eu e não-eu, definem as categorias que garantem que a realidade seja objetiva, por exemplo, a causalidade, a substancialidade ou a ação recíproca, o tempo e o espaço, bem como as categorias práticas da nossa relação com a realidade, nomeadamente o esforço, a aspiração ideal ou o sentimento. Estas relações constituem a realidade objetiva, e estas mesmas relações são, segundo Fichte, a condição da nossa consciência de nós próprios e da nossa experiência. As categorias são as ações pelas quais o eu toma consciência de si e das suas experiências, e isto deve garantir que as categorias são aplicáveis à realidade, estabelecendo-se então o espaço propriamente transcendental como espaço de existência objetiva, entre a lógica formal, de um lado, e o domínio empírico, do outro - o espaço que, para Maimon, era criado pela imaginação, como uma "faculdade de invenção" sem validade objetiva. Assim alcança Fichte a necessária aplicabilidade das categorias à realidade de que podemos ser conscientes - afinal a mesma questão a que a dedução transcendental de Kant tinha tentado responder, de modo menos aprofundado. Os Fundamentos da Doutrina da Ciência de 1794/1795 são, assim, uma ampliação e demonstração sistemáticas, a partir de princípios primeiros, da Dedução Transcendental da Crítica da Razão Pura.

No entanto, como se referiu, Fichte recebe de Maimon duas ideias da maior importância, nomeadamente: a função da imaginação e o problema da incompletude. Viu-se que a imaginação, segundo Maimon, tem a função de ligar as diversas características do objeto numa série coerente no espaço e no tempo. ${ }^{25}$ Ela constitui, assim, objetos contingentes e meramente possíveis, que não podem ser constituídos numa unidade espácio-temporal por uma regra necessária do entendimento. O estatuto da imaginação, porém, é o de uma "invenção", uma construção subjetiva, cuja objetividade é sempre incompleta, apenas assimptótica e projetada, segundo a já referida teoria das ideias do entendimento.

Em consonância com a sua fundamentação da objetividade da realidade, Fichte não pode deixar de atribuir à imaginação uma função transcendental objetiva, constitutiva ou determinante. $\mathrm{O}$ objeto é determinado pela imaginação numa unidade espacial e numa sequência temporal, que está sempre incompleta, mas segundo Fichte o resultado não é um mundo empírico sem regularidades a priori. É, pelo contrário, uma realidade objetiva à qual as categorias do entendimento podem ser aplicadas. A imaginação produtiva, segundo Fichte, é uma "faculdade maravilhosa do espírito humano sem a qual nada pode ser explicado no espírito humano, $[. .$.$] e sobre a qual se poderia facilmente fundar o mecanismo inteiro do espírito$

\footnotetext{
25 Para uma comparação do "Erdichtungsvermögen" segundo Maimon, e a imaginação transcendental de Fichte, vide Beiser, "Maimon and Fichte," 239-242.
} 
humano." ${ }^{26}$ Esta é a faculdade que permite unificar, embora numa permanente oscilação, a espontaneidade da razão e a sua atividade infinita com a passividade e limitação do dado da sensibilidade.

Por outro lado, reaparece também em Fichte a noção leibniziana de Maimon, de que a sensibilidade consiste num entendimento incompleto. Mas a incompletude não é, para o primeiro, apenas um modo de descrever a relação entre o entendimento e a sensibilidade. Ela não é somente aceite como um facto que descreve essa relação, entre faculdades da razão, mas é sistematicamente deduzida, e mostra-se que a incompletude é um elemento necessário e inseparável da consciência humana. Fichte mostra que a incompletude é um elemento necessário à reflexão e à consciência, e que a razão humana está dividida necessariamente em entendimento e sensibilidade, atividade e passividade.

Assim, as duas estratégias centrais de Fichte contra o ceticismo são, em primeiro lugar, estabelecer um princípio capaz de resistir à crítica cética por autofundamentação, o que encontra na razão prática, a qual, Fichte acredita, é autofundada; e, segundo, argumentar de modo sistemático, que todas as partes da razão são interdependentes. A própria existência da consciência humana não é compatível com as teses céticas da inexistência de princípios a priori, universais e necessários para a experiência. O nervo da resposta de Fichte a Maimon é, então, a demonstração de que a consciência não poderia existir sem a aplicabilidade das categorias. ${ }^{27}$

Fichte não apresenta, porém, as suas propostas contra o ceticismo como alguma forma de retorno, recuo ou sequer defesa contra as armas do ceticismo. Pelo contrário, entende que a sua Doutrina da Ciência veste essas mesmas armas contra o "criticismo dogmático", levandoas às suas últimas consequências, e indo mesmo, finalmente, além do ceticismo. Fichte pensa no que está em geral de acordo com o modo como Hegel tratará a questão nos anos seguintes que o ceticismo peca por estar ainda fixado nos dados positivos da experiência e da consciência, ou seja, que na verdade os céticos pós-kantianos, como Maimon ou Schulze, aceitam sem discussão demasiado daquilo que é presente ao conhecimento como dado. Não são, por isso, suficientemente céticos. Absolutamente nada pode ser aceite como um facto dado, e o ceticismo não é suficientemente cético enquanto aceitar factos da experiência como tal. $\mathrm{O}$ verdadeiro ceticismo, que implica pôr em causa todo o dado e só aceitar o que possa ser produzido por

\footnotetext{
${ }^{26}$ Fichte, GA I/2, 353.

${ }^{27}$ Isto não garante, é claro, a verdade de nenhuma aplicação particular das categorias a algum objeto, por exemplo, que uma determinada relação causal se aplica a algum objeto em particular. Segundo Fichte, para refutar a dúvida cética de Maimon não é preciso garanti-lo em nenhum caso particular, mas garantir somente a aplicabilidade geral. A minha argumentação sublinha, assim, alguns pontos diferentes da argumentação de Breazeale e de Beiser (Beiser, "Maimon and Fichte," 242-243; Breazeale, "Skepticism and Wissenschaftslehre," esp. 259).
} 
princípios ou formas do pensar, é a pedra de toque de uma filosofia que se pretenda verdadeiramente científica. ${ }^{28}$ Estes princípios, por sua vez, só são verdadeiramente princípios se forem capazes de, como diz o autor, "genetizar" o dado, ${ }^{29}$ ou seja, exibir a sua fonte nos atos autofundados da razão. Os dados devem ser substituídos pela plena liberdade da produção.

Alguns anos mais tarde, em 1804, Fichte entenderá todo o dado fáctico como assente sobre uma "disjunção" entre elementos do pensamento (disjunção, por exemplo, entre a consciência e o seu objeto, o teórico e o prático, conceito e intuição, e outras). E a menos que conheçamos a sua raiz comum, toda a disjunção ou dualidade é um mero dado de facto, e tem portanto de ser recusada como fundamento para a experiência ou para qualquer conhecimento ao nível conceptual. A tarefa da Doutrina da Ciência é a de "genetizar" os dados de facto, ou seja, não aceitar as disjunções na sua facticidade, mas como produzidas pelo pensamento. A "genetização" é realizada mostrando que as disjunções têm a sua origem nas condições de possibilidade do fenómeno.

Fichte entende esta recusa radical de todo o dado como uma incorporação plena do ceticismo na Doutrina da Ciência, e declara então sobre o ceticismo: "justamente o possuidor da Doutrina da Ciência, que tem o panorama de todas as disjunções na consciência, poderia [...] erigir um ceticismo que aniquilaria completamente tudo o que até aqui se admitiu, [...] um ceticismo perante o qual mesmo aqueles que até aqui se entretiveram como passatempo com toda a espécie de ceticices [Skeptisirerei] ficariam assustados e clamariam: a brincadeira foi longe demais!"30

\section{Hegel, o ceticismo antigo e o ceticismo pós-kantiano}

Se uma característica central do pós-kantismo foi a de prosseguir a crítica à metafísica, e a adoção de alguns elementos céticos para levar a cabo essa crítica, Hegel deve ser considerado ainda como parte do movimento pós-kantiano. No seu escrito de 1802 sobre a relação do ceticismo com a filosofia, Hegel expõe a relação entre o ceticismo e a filosofia, e compara o ceticismo antigo com o moderno. A ocasião para a tomada de posição sobre o ceticismo é uma recensão à obra de Schulze do ano precedente, a Crítica à Filosofia Teórica

\footnotetext{
${ }^{28}$ Conforme evidenciado por Breazeale "a Doutrina da Ciência de Fichte pressupõe o ceticismo bem como a sua crítica à metafísica dogmática e ao senso comum" (Breazeale, "Skepticism and Wissenschaftslehre", 264).

${ }^{29}$ Vermeiren ("Radical Immanence of Thought and the Genesis of Consciousness: Salomon Maimon", 276) mostra que a ideia de um "genetic transcendentalism" está já presente em Maimon.

${ }^{30}$ Fichte, GA II//8, 196 - tradução minha.
} 
(Kritik der theoretischen Philosophie). ${ }^{31}$ A recensão de Hegel é francamente negativa, devido aos insuficientes conceitos de metafísica, de ceticismo e de filosofia apresentados por Schulze. No que se refere à metafísica, Schulze entende-a como a doutrina de objetos enquanto coisas (Dinge) suprassensíveis ocultas detrás das aparências. Por isso, diz Hegel, “o Sr. Schulze é completamente incapaz de representar o racional, o em-si, senão como um rochedo debaixo da neve." ${ }^{32}$ E o mesmo se aplica à sua compreensão tosca da filosofia de Kant, segundo Hegel como "o mais obtuso dogmatismo, com um fenómeno e coisas em si escondidos atrás dos fenómenos como animais selvagens [unbändige] escondidos atrás dos arbustos dos fenómenos." 33

Uma parte importante do trabalho de Hegel com o ceticismo, e também com a metafísica, é o de refutar esta compreensão da coisa em-si e do objeto suprassensível da metafísica, mostrando que esta concepção grosseira nunca correspondeu nem à metafísica antiga, nem à metafísica moderna, nem à filosofia crítica, nem a "filosofia" nenhuma. Conforme se verá ainda, esta recensão deve ser considerada como um programa para a Fenomenologia do Espírito, que o autor realizará cinco anos mais tarde. As concepções gerais do "em-si” (an sich), da consciência, do ceticismo e da negatividade, características da obra de 1807, estão programaticamente esboçadas nesta recensão de 1802.

Hegel chama a este "recentíssimo ceticismo" 34 um "ceticismo dogmático" "35 não por, de algum modo, afirmar dogmaticamente o ceticismo, mas pela imagem grosseira que faz da metafísica e da filosofia crítica. Esta é, basicamente, a mesma imagem distorcida do conhecimento como um instrumento ou um meio para chegar até às coisas em si, situadas além do que nos aparece, imagem cujas incongruências e contrassensos Hegel tratará de expor na Introdução à Fenomenologia do Espírito. ${ }^{36}$ Conforme Hegel enunciará nesta obra, o

\footnotetext{
${ }^{31}$ Sobre o papel do ceticismo em Hegel, v. K. Vieweg, Skepsis und Freiheit. Hegel über den Skeptizismus zwischen Philosophie und Literatur, Wilhelm Fink, München, 2007; para um aprofundamento da relação entre filosofia transcendental, dialética e ceticismo também K. Vieweg, "A Defesa Siciliana de Hegel: a Relação da Lógica da Essência com a Metafísica, o Ceticismo e a Filosofia Transcendental", in: Revista Opinião Filosófica, 8, n. 2 (2017), pp. 69-84 (http://periodico.abavaresco.com.br/index.php/opiniaofilosofica/article/view/796); e os comentários em J. Kozatsas et al. (Eds.), Hegel and Scepticism: On Klaus Vieweg's Interpretation, De Gruyter, Berlin/Boston, 2017. Para uma exposição do tratado de Schulze, vide tb. Heidemann, Der Begriff des Skeptizismus, 146ss. O livro de Heidemann's inclui também um estudo do ceticismo tomando em atenção o ceticismo antigo, a resposta "integrative" e "imunisierend" de Hegel, e a discussão contemporânea. Segundo Heidemann, a resposta de Hegel ao ceticismo deveria ser caracterizada como um "integrative Antiskeptizismus", que é explicado como se segue: "o anticeticismo integrativo procura então a sua imunização não através da eliminação do ceticismo, mas pela sua aceitação como um problema filosófico sistemático inevitável, mas controlável" (134).

${ }^{32}$ Hegel, Werke 2, 220.

${ }^{33} \mathrm{Ib} ., 269$.

${ }^{34} \mathrm{Ib} ., 253$.

${ }^{35} \mathrm{Ib} ., 251$.

${ }^{36}$ Vide Heidemann, Der Begriff des Skeptizismus, 207-208.
} 
conhecimento não é uma relação entre um sujeito e um objeto "fora" do sujeito, situados em alguma espécie de lugares separados por um hiato ou meio indefinível. E tão-pouco é a verdade uma comparação entre os dois, como se fosse possível ou se fizesse qualquer sentido conhecer o objeto conforme se dá à consciência, e conhecê-lo ainda de outra maneira, nomeadamente como se dá em si, para poder então comparar os dois acessos, a partir de uma outra posição ainda mais elevada, e aferir da verdade ou falsidade de um conhecimento. O conhecimento, pelo contrário, é uma conjuntura de experiências, significados e conceitos que correspondem a um mundo significativo, complexo e definido, onde uma linguagem e um pensamento fazem unicamente sentido, conjuntura que Hegel denomina uma "figura da consciência". A consciência é uma comparação entre o objeto tal como é 'para nós' e 'em si', mas a tomada de consciência desta comparação é justamente a passagem a uma nova e mais elevada figura da consciência. O objeto não é jamais dado verdadeiramente 'em si mesmo', mas somente aparece como tal em cada figura da consciência. A verdade não é, certamente, uma correspondência entre sujeito e objeto como duas coisas separadas e puras, mas a relação de uma figura da consciência em relação a uma outra que ela vem substituir num processo sucessivo.

Os animais selvagens "indomados" que, segundo a compreensão grosseira da metafísica e da filosofia crítica, espreitam ainda em liberdade para lá dos arbustos dos fenómenos, não estão na verdade, de acordo com Hegel, na floresta inacessível além dos fenómenos. Estão, pelo contrário, neles presentes como o seu lado negativo, a negatividade que é inerente ao conhecimento, a que Hegel chama o "lado livre" da filosofia. O em-si, a verdade, que é o 'indomado', reside na própria negatividade inerente aos fenómenos. Dado que a verdade não é uma relação com algo de exterior e independente do sujeito, mas a substituição de uma figura da consciência por outra, a coisa em-si não é como um rochedo oculto sob um manto de neve, mas o lado negativo e livre do conhecimento. O ceticismo não é, por conseguinte, uma dúvida acerca da possibilidade de conhecermos objetos para além do que aparece, isto é, dos factos presentes à nossa consciência, conforme Schulze e o ceticismo moderno o entendem. O ceticismo não é sequer uma dúvida, mas a dialética dos fenómenos, a negatividade integrante deles, que os corrói e refuta por dentro, pela lógica inerente da consciência.

Por outro lado, como dirá Hegel nas Lições sobre a História da Filosofia, e ao contrário do ceticismo moderno que exprime dúvida, o ceticismo antigo "não duvida, mas tem a certeza da inverdade. ${ }^{37}$ Hegel louva o ceticismo antigo por não se ter centrado na dúvida sobre se aos

\footnotetext{
${ }^{37}$ Hegel, Werke 19, 362.
} 
conteúdos factuais da consciência correspondem objetos em si, mas por ter estabelecido "em

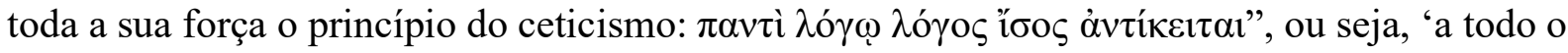
logos opõe-se um outro, de igual força. ${ }^{38}$ Ao contrário do ceticismo moderno, que permanece preso aos factos da consciência e apenas põe em dúvida o seu estatuto, a importância do ceticismo antigo é que nos permite reconhecer que "toda a filosofia verdadeira tem necessariamente também um lado negativo." "39 Em consequência, "o ceticismo está intimamente unido a toda a filosofia verdadeira, e há, por conseguinte, uma filosofia que não é nem ceticismo, nem dogmatismo, e que é também ambos simultaneamente." 40 A tese assim anunciada é que a filosofia tem um lado negativo, que coincide com o ceticismo, e um outro positivo, que não é senão o resultado da resolução da antinomia dialética presente em tudo o que é finito - em qualquer tese ou objeto. O ceticismo é assim, declara Hegel, "o começo da filosofia," ${ }^{41}$ e no seu lado positivo inclui um momento do dogmatismo que não tem, contudo, o significado que o ceticismo moderno lhe atribui, mas apenas o de afirmar o resultado positivo da negação antinómica de qualquer ser finito.

Esta primeira reflexão sobre o ceticismo está, como se disse, na base da Fenomenologia do Espírito, que Hegel define explicitamente como "o ceticismo que se consuma [sich vollbringender Skeptizsmus]. ${ }^{42}$ Nesta obra, são sucessivamente refutadas todas as figuras da consciência pela explicitação da sua oposição e contradição implícitas, partindo do nível mais rudimentar, i.e., a consciência sensível - e daí a crítica acérrima à aceitação inquestionada, como tal, dos factos sensíveis da consciência pelo ceticismo moderno. Pelo contrário, no ceticismo consumado da Fenomenologia a consciência faz a experiência da sua própria insuficiência e da contradição dos seus alegados "factos". Também, conforme ensinado pelo ceticismo antigo, o processo de refutação das sucessivas figuras da consciência é o momento negativo, a negatividade implícita em cada uma delas. O que a Fenomenologia acrescenta ao ceticismo antigo, porém, é que a negatividade tem um resultado positivo, i.e., a verdade como uma nova figura da consciência.

Na Fenomenologia do Espírito, o ceticismo é tanto uma figura geral, presente em todas as figuras da consciência, como também um momento específico, ${ }^{43}$ que corresponde à liberdade

\footnotetext{
${ }^{38}$ Sobre o tratamento da questão da "equipolência" vide Forster, Hegel and Skepticism (Harvard U. P., Cambridge, Mass, 1989) 28, 32, 106-109.

${ }^{39}$ Hegel, Werke 2, 227.

${ }^{40} \mathrm{Ib}$.

${ }^{41} \mathrm{Ib} ., 240$.

${ }^{42}$ Hegel, GW 9, 56.

${ }^{43}$ Sobre estes temas leia-se Paredes-Martín, "Escepticismo y dialética" (in Still Reading Hegel: 200 Years After the Phenomenology of Spirit, ed. E. B. Pires, Imprensa da Universidade de Coimbra, Coimbra, 2009, 199-211).
} 
conforme descoberta no final do mundo antigo. Perante o desaparecimento da substância ética de um mundo, o pensamento voltou-se para si, descobriu e realizou a sua própria liberdade, onde não há verdade, mas somente a sua própria certeza de si. O significado do ceticismo, como uma figura da consciência é que a negatividade, que antes do ceticismo era somente em si tornase então para si. Assim,

o dialético, enquanto movimento negativo, tal como este é imediatamente, aparece de início à consciência como algo a que esta está entregue, e que não é por meio dela. Com o ceticismo, contudo, este movimento é um momento da consciência de si, à qual não acontece que o seu verdadeiro e o seu real desaparecem sem que ela saiba como; mas um momento tal que, na certeza da sua liberdade, faz desaparecer este outro que se dá como real." 44

O ceticismo é a tomada de consciência da liberdade do pensamento e do momento negativo do conhecimento, quando o movimento destrutivo do pensamento não mais é sofrido passivamente pelo pensamento, mas conscientemente realizado (Fichte diria, "genetizado").

Mas perante a evidência de que mesmo a mais simples ação da vida exprime uma crença no objeto e a sua afirmação, o ceticismo enferma historicamente da contradição entre a sua certeza de si próprio na sua liberdade e na anulação do objeto, certeza que reafirma a consciência como igualdade consigo mesma, por um lado, e, por outro, a "total desigualdade" consigo mesma dessa certeza, provocada pela impossibilidade de unificar de modo coerente a sua ação e a sua doutrina. ${ }^{45}$ A tomada de consciência desta contradição corresponde à divisão e duplicação da consciência de si, e a uma nova figura da consciência, a consciência infeliz, com que se encerra o capítulo fenomenológico do ceticismo.

Nos textos dos anos 20 das Lições sobre a História da Filosofia retorna a análise do ceticismo como momento negativo da filosofia. "De facto," lê-se, "se alguém quer ser pura e simplesmente um cético, ele não pode ser refutado, ou seja, não pode ser conduzido à filosofia positiva." ${ }^{" 46}$ Este cético, incapaz de verdade, é comparável a um paralítico, que não pode ser convencido a andar. O cético instalou-se no nada, e "afinal," comenta Hegel, "não se pode expulsar alguém do nada." ${ }^{47}$ Situando-se na completa negatividade, o cético não está em lugar nenhum, nem tem nenhuma posição e não pode por isso ser levado para fora desse não-lugar ou dessa posição inexistente. Assim, se o ceticismo é um momento negativo necessário à filosofia, a negação cética não é a verdadeira negatividade, na medida em que o cético não

\footnotetext{
${ }^{44} \mathrm{Ib} ., 119-120$.

${ }^{45}$ Cf. ib., 120-121.

${ }^{46}$ Hegel, Werke 19, 359 - tradução minha.

${ }^{47} \mathrm{Ib}$.
} 
compreende que a negação é uma determinação, ou seja, que produz necessariamente um conteúdo e, por conseguinte, um resultado.

Apesar disso, o ceticismo é, para Hegel, uma consciência lógica superior, visto que descobre e traz à consciência a essência do conteúdo categorial dos pensamentos. ${ }^{48}$ Desta perspectiva, o ceticismo não é mais do que a tomada de consciência da lógica inerente a toda a determinação, que é a de gerar uma inevitável referência ao seu oposto. Hegel dá o exemplo do ponto geométrico que, por um lado, é uma determinação espacial, está situado no espaço, mas, por outro, não tem dimensão e não está, por isso, no espaço. Se o ponto tem um significado, ele é simultaneamente espacial e não espacial. Esta dialética do ponto significa que ele, "porque é o limite do espaço, é a negação do espaço," 49 sendo simultaneamente também o que permite determinar o espaço. E o mesmo acontece com todas as categorias e conceitos determinados, que contêm em si a referência ao seu oposto.

O ceticismo é, então, segundo Hegel, a exposição da insuficiência da lógica do entendimento, e a consciência filosófica das categorias e da sua antinomia interna. O único modo de ir além dele é a compreensão da lógica da determinação e, consequentemente, a compreensão de que as proposições ou conceitos opostos não são exclusivos, mas que se podem reunir em sistemas melhor organizados. A razão dialética mostra que qualquer tese, proposição ou conceito implica o seu oposto, sem que isto signifique, no entanto, a supressão do princípio da não-contradição numa indeterminação e indiferenciação entre qualquer afirmação e o seu oposto. Não sendo possível aqui estudar mais além a concepção hegeliana deste princípio, refira-se somente que a recusa do princípio da não-contradição significa a sua recusa e a sua aceitação simultâneas, segundo aspectos diferenciáveis. Em geral, Hegel chama de contradição "dialética" o facto de que o oposto está contido em tudo o que é posto, como uma referência necessária implícita, que está contido, por assim dizer, enquanto ausente, como aquilo que ele não é, mas cuja exclusão é constitutiva daquilo que é posto.

Nas Lições sobre a História da Filosofia Hegel revê os três tropoi acima referidos sobre a fundamentação do conhecimento, nomeadamente o do retorno ao infinito, da pressuposição e da circularidade. Como se disse, no retorno ao infinito não se encontra uma fundamentação, porque qualquer termo definido carece de fundamentação; na pressuposição tão-pouco se encontra fundamentação, uma vez que a arbitrariedade do pressuposto admitido significa justamente a recusa de uma fundamentação; na circularidade, finalmente, mais uma vez todos

\footnotetext{
${ }^{48}$ Cf. ib. 388 .

${ }^{49}$ Ib. 396.
} 
os termos envolvidos carecem de fundamentação. Hegel esclarece que a filosofia especulativa resolve o problema da fundamentação, porque ela "não tem nenhum princípio" e não precisa de nenhum. A fundamentação é dada, antes, a partir da refutação e inclusão sistemática das teses refutadas, enquanto tal, num processo sempre renovado em que a verdade é, a cada momento, a verdade relativa da tese que refuta em relação à tese precedente refutada.

Este é o processo que podemos observar, finalmente, na Ciência da Lógica. Esta não tem princípio, e não carece de nenhuma fundamentação, porquanto o seu ponto de partida - o puro ser sem determinação - não tem conteúdo e, como o ceticismo, nada afirma nem reivindica. Este ponto de partida é, por isso, a sua própria refutação e anulação, com o que é lançado um processo de refutação e produção sucessiva e sistemática de novos conceitos e teses. A conclusão da Ciência da Lógica é o autoesclarecimento integral da própria ideia que tãopouco pode ser refutada porque integra todas as oposições categoriais registadas na história da filosofia e produzíveis numa linguagem categorialmente desenvolvida, capaz de reflexão e autoesclarecimento.

\section{Nota conclusiva: ceticismo e filosofia}

Para concluir, poderíamos retornar ao início e passar de Maimon até Hegel por uma via bem mais curta do que aquela que aqui tentei seguir. De facto, o ceticismo não é apenas algo de diferente e diverso da filosofia mas, dado que se opõe a qualquer verdade, o ceticismo é o total oposto da filosofia. Mas se é assim, devemos concluir com as seguintes palavras de Maimon, que poderiam também servir de epígrafe a este estudo: "Deve notar-se que a oposição, ao contrário do que se acredita comummente, separa menos as coisas entre si do que a diversidade. Porque as coisas que são opostas entre si se explicam mutuamente através dessa mesma oposição; o mesmo não acontece, porém, com a coisas que são diversas uma da outra." ${ }_{50}$ Por isso, segundo a lógica da determinação invocada por Maimon, o ceticismo e a filosofia estão tão ligados entre si.

\section{Referências bibliográficas}

\footnotetext{
50 "Es ist merkwürdig, daß die Entgegensetzung die Dinge weniger von einander trennt, als die Verschiedenheit (das Gegenteil von dem, was man gemeiniglich glaubt): indem die Dinge, die einander entgegengesetzt sind, sich durch diese Entgegensetzung selbst einander erklären; nicht so aber die Dinge, die von einander verschieden sind." (Maimon, Versuch, 142)
} 
Albert, Hans: Traktat über kritische Vernunft, Tübingen: J. C. B. Mohr (Paul Siebeck), 1991.

Beiser, Frederick C.: "Maimon and Fichte," in Salomon Maimon: Rational Dogmatist, Empirical Skeptic: Critical Assessments, ed. Gideon Freudenthal, Boston: Kluwer, 2003, 233248.

Breazeale, Daniel: "Fichte, Skepticism, and the "Agrippan Trilemma", in Fichte-Studien 44 (2017), 3-16.

Breazeale, Daniel: "Skepticism and Wissenschaftslehre". in Daniel Breazeale, Thinking Through the Wissenschaftslehre: Themes from Fichte's Early Philosophy, Oxford: Oxford University Press, 2013.

Ferrer, Diogo: O Sistema da Incompletude: A Doutrina da Ciência de Fichte de 1794 a 1804, Coimbra: Imprensa da Universidade de Coimbra, 2014.

Fichte, Johann Gottlieb: Gesamtausgabe der Bayerischen Akademie der Wissenschaften, ed. R. Lauth e H. Gliwitzky, Hamburg: Feliz Meiner, 1962ss. [=GA]

Forster, Michel N.: Hegel and Skepticism, Cambridge, Mass.: Harvard University Press, 1989.

Guéroult, Martial: La philosophie transcendantale de Salomon Maimon, Paris: Félix Alcan, 1929.

Hegel, Georg Wilhelm Friedrich: Gesammelte Werke, ed. W. Bosiepen e R. Heede, Hamburg: Felix Meiner, 1980, vol. 9. [=GW]

Hegel, Georg Wilhelm Friedrich: Werke, ed. E. Moldenhauer e K. Michel, Frankfurt a. M.: Suhrkamp, 1969.

Heidemann, Dietmar H.: Der Begriff des Skeptizismus: Seine systematischen Formen, die pyrrhonische Skepsis und Hegels Herausforderung, Walter de Gruyter: Berlin / New York, 2007.

Herrera, Hugo Eduardo: "La discusión de Salomon Maimon con el intento de vinculación de sensibilidad y entendimiento en la Crítica de la razón pura de Immanuel Kant," in Anuario Filosófico, XLIII/3 (2010), 561-587.

Kozatsas, Jannis et al. (eds.): Hegel and Scepticism: On Klaus Vieweg's Interpretation, Berlin/Boston: De Gruyter, 2017.

Léon, Xavier: Fichte et son temps II: Fichte à Berlin (1799-1813), Paris: Armand Colin, 1924.

Maimon, Salomon: Streifereien im Gebiete der Philosophie, in Gesammelte Werke, vol. 4, ed. Valerio Verra, Hildesheim: Georg Olms, 1970.

Maimon, Salomon: Versuch über die Transzendentalphilosophie, ed. F. Ehrensperger, Hamburg: Felix Meiner, 2004. 
Paredes-Martín, María del Carmen, "Escepticismo y dialética", in Still Reading Hegel: 200 Years After the Phenomenology of Spirit, ed. E. Balsemão Pires, Coimbra: Imprensa da Universidade de Coimbra, 2009, 199-211.

Vermeiren, Florian: "Radical Immanence of Thought and the Genesis of Consciousness: Salomon Maimon", in Kant-Studien (2019) 110/2, 272-289.

Vieweg, Klaus: "A Defesa Siciliana de Hegel: a Relação da Lógica da Essência com a Metafísica, o Ceticismo e a Filosofia Transcendental”, in Revista Opinião Filosófica, 8, n. 2 (2017), pp. 69-84

(http://periodico.abavaresco.com.br/index.php/opiniaofilosofica/article/view/796)

Vieweg, Klaus: Skepsis und Freiheit. Hegel über den Skeptizismus zwischen Philosophie und Literatur, München: Wilhelm Fink, 2007 